\section{Glacial and Interglacial Patterns for Asian Dust Transport}

Atmospheric interpretations based on elemental mass-particle size distributions (MSDs) have shown that the Chinese loess/ paleosol sediment is composed mainly $(\sim 90 \%$ of total mass) of eolian mineral dust that originated from the major desert-sources for Asian dust situated in northern and northwestern China. The dust storms and dustfall events in inland China provide the physical basis for the eolian theory of loess origin. Seasonal peaks in dust concentrations over the open North Pacific also have been linked to the occurrence of dust storms in Asia.

Recently, we estimated the dust-derived elemental deposition rates to the Loess Plateau using data for dust storm (DS) and nondust storm (N-DS) periods. Two major findings of the studies were (1) that dry deposition was more important than wet deposition in terms of annual dust flux; and (2) that on a long-term basis, the dry input of dust to the loess was mainly due to normal transport conditions, i.e., days on which dust was suspended in the atmosphere but dust storms were not reported as part of the routine meteorological observations. This second finding was unexpected because it contrasts with the interpretation that the loess accumulations are mainly attributable to strong dust storms and dustfall events. Furthermore, this conclusion has generated some controversy in relation to the hemispheric to global-scale transport of Asian dust.

Here we further compare data for the particle size distributions in present atmospheric aerosol samples $(\mathrm{Al})$ with data for the last-interglacial paleosol (S1) and the Malan, last glaciation, loess (L1) from the well-known Luochuan loess / paleosol sequence. The major purpose of comparing the source materials with the sedimentary deposits is to evaluate the relative importance of DS vs. N-DS processes for dust transport during glacial and interglacial intervals. Particle size distributions (PSDs) also are used to evaluate the patterns for Asian dust transport over regional and greater spatial scales. The regional-scale transport of Asian dust during interglacial stages is suggested to be mainly attributable to $\mathrm{N}-\mathrm{DS}$ processes and is dominated by northwesterly surface winds. Conversely, during glacial stages the impact of dust storms on the accumulation of loess is enhanced. These regional effects are in contrast to the global-dispersal of dust that is associated with transport by upper-level westerly winds and is mainly the result of desert dust storms during both glacial and interglacial conditions. Temporal differences in the dust transport patterns to the Loess Plateau suggest that the variability in the coarse particle fraction ( $>20$ micron) during interglacial times is not directly attributable to the strong dust storms and dust fall events that have been linked to a strengthening of East Asian winter monsoonal winds. This is in contrast to the dust deposition rates that are strongly influenced by the monsoonal circulation.

Xiao Y. Zhang and ZHI S. AN

State Key Laboratory of Loess \& Quaternary Geology, Chinese Academy of Sciences, P.O. Box 17

Xian 710054, China

\section{R. ARImoto}

Carlsbad Environmental Monitoring \& Research

Center, New Mexico State University,

1400 University Drive, Carlsbad,

New Mexico 88220, USA

\title{
East Asian Monsoon Variations during the Last Interglacial: Evidence from the Northwestern Margin of the Chinese Loess Plateau
}

Climate changes during the last interglacial may serve as an analog for future global changes. However, our current understanding of the last interglacial climate is still limited. Although the Chinese loess-paleosol sequence is widely recognized as one of the best terrestrial Quaternary climatic recorders, the paleosol S1 in the central Loess Plateau area, where most of studies have been conducted, is too thin (ca. $2 \mathrm{~m}$ ) to yield high-resolution climatic records of the last interglacial.

However, the thick aggradational paleosol S1 (6-8 $\mathrm{m})$ in the northwestern margin of the Chinese Loess Plateau, has preserved high-resolution records which provide considerable insight into the temporal variations of the East Asian monsoon and thus shed new light on the forcing factors. The paleosol S1 at the two sections investigated here consists of five sub-units: three well-developed paleosols and two interbedded loess layers. According to the modeled ages based on the depth of the Blake paleomagnetic event and TL dates, the three paleosols developed in marine oxygen isotope stage (MIS) 5a, 5c, and 5e, and the two loess layers were deposited in MIS $5 b$ and $5 d$, respectively. The frequency-dependent magnetic susceptibility, as well as the concentration of secondary carbonate, is used as an indicator of the summer monsoon intensity, and the median particle size as an indicator of the winter monsoon intensity.

The results suggest that the northwestern margin of the Chinese Loess Plateau experienced the strongest summer monsoon intensity in MIS 5e and the weakest in MIS 5a, among the three warmer periods during MIS 5 . The summer monsoon was weaker in MIS $5 \mathrm{~b}$ than in MIS $5 \mathrm{~d}$. A dusty interval interrupted the second warmer period $(5 \mathrm{c})$ and a soil-forming event interrupted the first colder period (5d). The results also suggest that the directions of changes in the intensities of summer and winter monsoons may not always have varied in inverse proportion. For example, the weakest summer monsoon occurred in MIS 5a during which the winter monsoon was not the strongest. We further conclude that the winter monsoon during the last interglacial was probably driven by global ice volume fluctuations, while the summer monsoon was primarily controlled by the northern hemisphere solar insolation and was probably modified by a feedback mechanism. That is, the climatic buffering effect of low latitude oceans may have distorted the response of the summer monsoon to insolation variations. Finally, our results do not contain evidence of climatic instability in MIS 5e, even though the study area is situated in a region which has been sensitive to climatic changes.
F.H. Chen and J.M. Wang

Department of Geography, Lanzhou University, Lanzhou, Gansu 730000, China

\section{J. Bloemendal}

Department of Geography, University of Liverpool, Liverpool, L69 3BX, UK

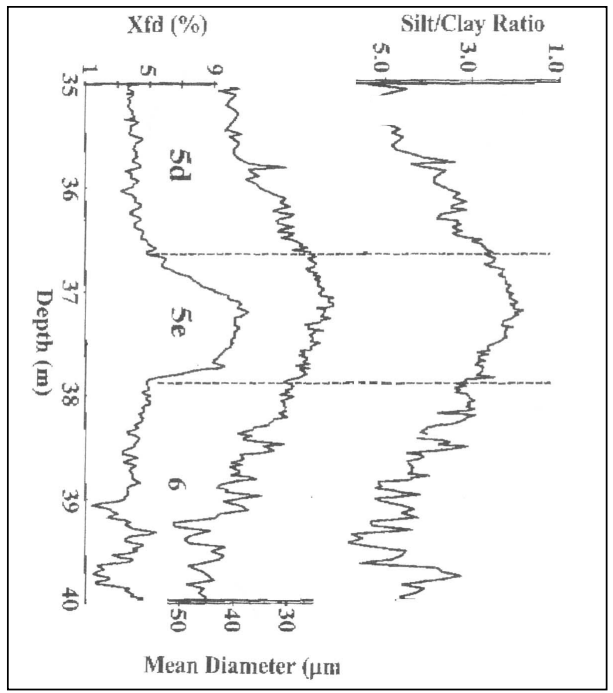

Fig. 12: Percentage frequency dependent magnetic susceptibility, mean particle diameter and clay-silt ratio variations through MIS $5 e$ in the semi-arid Xiniang Basin. Parallel results have been obtained from the semi-humid Linxia basin (see Chen, F.H., Bloemendal, J., Feng, Z.D., Wang, J.M., Parker, E. and Guo, Z.T., Quarternary Science Reviews, in Press). 